\title{
TOWARDS A PATTERN RECOGNITION APPROACH FOR STRATOPHENETICS
}

WEI, Kuo-Yen, Dept. of Geology and Geophysics, Yale University, P. O. Box 6666, New Haven, CT 06511-8130, U.S.A.

Stratophenetics has been widely adopted in paleontology to reconstruct phylogenetic trees. Despite the easy access to powerful computing facility amongst paleontologists, there is a shortage of integrated statistical procedures in such approach. This report is to (1) introduce a pattern recognition technique, Soft Independent Modeling of Class Analogy (SIMCA), for an objective stratophenetic approach, and (2) demonstrate its applicability by tracing two planktic foraminiferal lineages through a deep-sea sedimentary sequence.

Stratophenetics proceeds in three steps: (1) recognizing phena (groups of morphologically similar specimens) from each stratigraphic sample, (2) ordering stratigraphic levels in each local section, and (3) linking phena in adjacent chronostratigraphic intervals on the basis of overall morphological similarity. The Plio-Pleistocene planktic foraminiferal sequence of the Globorotalia (Globoconella) puncticulata-inflata plexus obtained from the Deep Sea Drilling Project site 588 serves a good illustration case. This sequence, dated at $3.66 \mathrm{Ma}$ to the Recent, is relatively complete and furnished with a good chronostratigraphy. It records the branching history of $G$, inflata form the $G$. puncticulata lineage. The gradation nature of the divergence and the enormous morphological variability in $G$. inflata have caused difficulty in achieving a consensus of taxonomy and phylogeny in this plexus.

Typical specimens of the two species, G. puncticulata and G. inflata, were identified from a stratigraphic level dated at $2.76 \mathrm{Ma}$. Principal component models were built to characterize the morphometric patterns of the two morphotypes using SIMCA. The Globoconella specimens of the two adjacent stratigraphic intervals, one above and one below (dated 2.74 Ma and $2.83 \mathrm{Ma}$, respectively), were evaluated against the models and classified into one of the two morphotypes. The newly classified specimens were then used to build new models for further tracing specimens in the next adjacent stratigraphic levels. Progression such training and classification procedures through the stratigraphic intervals resulted in a reconstruction of the evolutionary patterns of the two lineages. The cladogenesis is inferred to occur at about $3.5 \mathrm{Ma}$ and is characterized by a gigantism in the $G$. inflata lineage. The two lineages differ only in size and show similarity in all other characters in the beginning of the divergence, A disparity in allometric heterochrony further differentiated the two lineages after $2.8 \mathrm{Ma}$ and the trend continued until $G$. puncticulata became extinct at $2.35 \mathrm{Ma}$. 